\title{
Study on the Paths of Personnel Training in Colleges and Universities- Based on industry-enterprise-occupation oriented personnel demanding
}

\author{
Zhenyun Zhou ${ }^{1}$, Yiqi Mao ${ }^{1}$ and Daoming Wang ${ }^{2}$ \\ ${ }^{1}$ School of Accounting, Hangzhou Dianzi University, 310018 Hangzhou Zhejiang, China \\ ${ }^{2}$ Center of Employment and Entrepreneurship, Hangzhou Dianzi University, 310018 Hangzhou Zhejiang, China
}

\begin{abstract}
For the sake of meeting the needs of enterprise socialization development, the appeals of students individualization growth, and the demands of universities specialization culture, how to carry out personnel training is a research topic which draws common concern both at home and abroad. Investigating university graduates demand distribution in different industries, enterprises and occupations, constructing the AEIOU method of hierarchical classification oriented demand, analyzing the distribution characteristics of personnel demanding, carding the adjustment mechanism of major setup, and perfecting the training mode of hierarchical classification, are all the research ideas of the personnel training paths oriented by industry-enterpriseoccupation demand.
\end{abstract}

Keywords. train path; personnel demand; personnel train; major setup; hierarchical classification; AEIOU

\section{Introduction}

As is known to all, there are three classic patterns of personnel training in universities: the Tsukuba mode based on the cluster, science for the organization of knowledge teaching, the MIT model characterized mainly by an interdisciplinary course, the Oxford model combined arts and Sciences through the composite course ${ }^{[1]}$. Compared with three classic patterns, the personnel training pattern based on personnel demand has become a hot topic of current research. Industry transition, enterprise reform and occupation change will affect the personnel demand of industry, enterprise and occupation. Personnel demand oriented by industry, enterprise and occupation will affect personnel train in Colleges and Universities. So personnel train paths match with personnel demand oriented by industry, enterprise and occupation. It will be discussed from those aspects, which are "how to match", "how to judge", and "how to realize".

\section{The match relationship between per- sonnel demanding and training}

Based on the analysis of GUSE employment model, government (G), universities (U), students (S) and enterprises (E) should participate in the university students' employment affairs together ${ }^{[2]}$. In the final analysis, GUSE model is trying to resolve the difficulty of the university students' employment as well as the problem of matching personnel demanding with personnel training.

\subsection{The bridge and tie of personnel demanding and training}

Major setup plays the role of bridge and tie. Major is one of the most closely ties linking universities with the society and must adapt to social change and demand; seeking the equilibrium of demand and reaction requires the effective mechanism through major setup and adjustment ${ }^{[3]}$. Based on the analysis of GUSE model, as shown in Figure 1, major setup should be subject to the "four factors": $\mathrm{G}, \mathrm{U}, \mathrm{S}$ and $\mathrm{E}^{[4]}$. Major setup is one of the specific employment affairs of specific employment field and one of ties and bridges matching personnel training with personnel demanding.

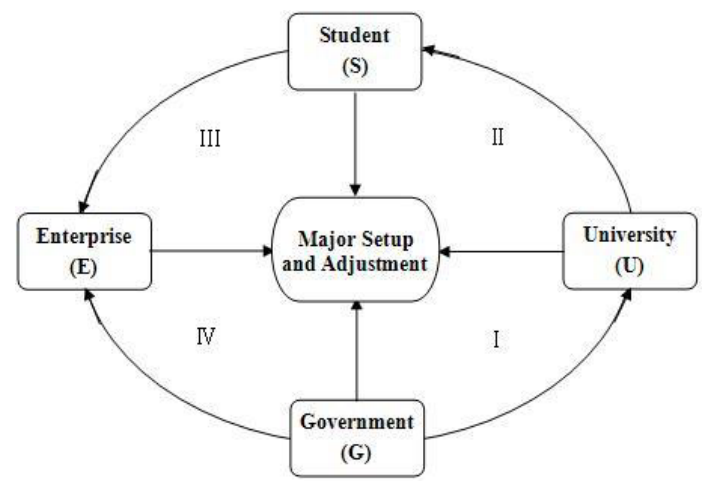

Figure 1. Relationship of major setup and adjustment.

The reason why major setup needs to be adjusted is because the personnel demanding adjustment of industry, 
enterprise and occupation will affect the regulation of personnel training. Major adjustment mechanism lies in the "five matches": the orientation of major setup is matching with the orientation of industry personnel demanding; the direction of major setup is matching with the direction of enterprise personnel demanding; the level of major setup is matching with the level of occupation demanding; the scale of major setup is matching with the scale of occupation demanding; the structure of major setup is matching with the structure of occupation demanding.

\subsection{The measures and methods of personnel demanding and training}

Hierarchical classification can lay down the proper measures and methods. According to enterprise development socialization, student growth personalization and university culture specialization, investigating personnel demanding distribution based on industry, enterprise and occupation respectively, and constructing the AEIOU method to analysis its levels and categories provide a path for the judgments of personnel demand characteristics, major setup ideas and personnel train paths. This is hierarchical classification based on the personnel demand -oriented, referred to as hierarchical classification ${ }^{[5]}$.

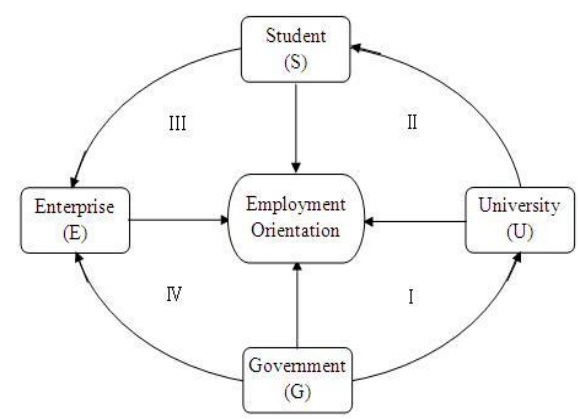

Figure 2. Employment-oriented relationship.

By analysis of GUSE model, demand-oriented hierarchical classification, not only provides an employment mechanism of university students for the collaboration of $\mathrm{U}, \mathrm{S}$ and $\mathrm{E}$ (U2S2E), but also innovates a training model for resolving the conflicts among the $\mathrm{U}, \mathrm{S}$ and $\mathrm{E}$, as shown in Figure 2. This training model called the hierarchical classification training model, referred to as hierar- chical classification model.

\subsection{The intersection and connection of person- nel demanding, training and major setup}

The oriented connotation is its intersection and connection. Oriented connotation, from the narrow sense, contains levels, scale and structure; from the broad sense, contains the orientation and direction as well. In the following content, the orientation is based on the macroscopic concept of industry; the direction is based on the mesoscopic concept of enterprise; the guidance is based on the microscopic concept of occupation.

Under personnel demand, the orientation, direction and guidance of personnel training depend on the orientation, direction and guidance of major setup; the orientation, direction and guidance of major setup depend on the orientation, direction and guidance of the personnel demanding; while the orientation, direction and guidance of personnel demanding depend on the professional demanding distribution of industry, enterprise and occupation. Therefore, the oriented connotation becomes the relevant point of personnel demanding, major setup and personnel training.

\section{The judgment approach of demand- oriented hierarchical classification}

\subsection{Innovating of hierarchical classification AEIOU method}

Demand-oriented AEIOU method is the analytic approach of dividing the importance for personnel demanding of industry, enterprise and occupation. This method is mainly using five vowels "A, E, I, O and U" to describe the levels and categories of personnel demanding, major setup and personnel training. This method is also known as hierarchical classification AEIOU method, referred to as AEIOU method. ${ }^{[5]} \mathrm{A}, \mathrm{E}, \mathrm{I}, \mathrm{O}, \mathrm{U}$ are the abbreviations of English words "Absolutely important, especially important, Important, Ordinary, Unimportant", Which respectively refers to "absolutely important, especially important, important, ordinary, unimportant" in personnel demanding and training, and "absolutely match, especially match, important match, ordinary match and unimportant match" in major setup, as shown in Table 1.

Table 1. AEIOU method.

\begin{tabular}{lll}
\hline Code & Level Category of Talent Demand & Level Category of Major Setup \\
\hline A & Absolutely Important Level Category & Absolutely matched Level Category \\
E & Especially Important Level Category & Especially matched Level Category \\
I & Important Level Category & Important matched Level Category \\
O & Ordinary Level Category & Ordinary matched Level Category \\
U & Unimportant Level Category & Unimportant matched Level Category \\
X & Unknown Level Category & Unknown matched Level Category \\
\hline
\end{tabular}

\subsection{Establishing of hierarchical classification AEIOU standard}

To make AEIOU analysis, there should be AEIOU standard in addition to AEIOU method. This standard is to establish a uniform metric in advance based on personnel demanding distribution of industry, enterprise and occupation. Personnel demanding distribution continuously shows dynamic characteristics, therefore it needs to survey the graduates' employment in recent years. It also 
presents focused features, therefore, it needs to analyze and judge the important information of demanding distribution.

This standard can be described by using reasonable indicators, namely absolute or relative proportion, absolute or relative value, cardinal or ordinal numbers, for analysis of the levels and categories of personnel de- manding, major setup and personnel training, as shown in Table 2. In analyzing the categories of major setup, it can based on whether there are specialized courses, compulsory courses, limit-selected courses, elective courses, optional courses that are matching with personnel demanding distribution characteristics, thereby defining the categories of the current major setup.

Table 2. AEIOU standard.

\begin{tabular}{llll}
\hline Level category & Industry standard & Enterprise standard & Occupation standard \\
\hline A & Proportion greater than or equal to $30 \%$ & Talent demand greater than or equal to 20 & Proportion greater than or equal to 30\% \\
E & Proportion greater than or equal to $20 \%$ & Talent demand greater than or equal to 15 & Proportion greater than or equal to 20\% \\
I & Proportion greater than or equal to 10\% & Talent demand greater than or equal to 10 & Proportion greater than or equal to 10\% \\
O & Proportion greater than or equal to $8 \%$ & Talent demand greater than or equal to 5 & Proportion greater than or equal to 5\% \\
U & Proportion greater than or equal to 3\% & Talent demand greater than or equal to 3 & Proportion greater than or equal to 1\% \\
X & Proportion less than 3\% & Talent demand less than 3 & Proportion less than 1\% \\
\hline
\end{tabular}

\subsection{Judging of hierarchical classification AEIOU analysis}

The steps of hierarchical classification AEIOU judgment are as follows: Firstly, to investigate relevant personnel demanding distribution, such as the distribution of industry, enterprise, occupation; Secondly, to establish hierarchical classification judgment standard, such as the standard of enterprise demand and major setup; Thirdly, to assess hierarchical classification AEIOU, such as the levels and categories of occupation demand and major setup. Fourth, to judge the match degree of personnel demand and major setup, to build adjustment mechanism and training path, such as the training path based on industry demand.

\section{The realization paths of demand- oriented personnel training}

\subsection{The training paths based on industry- oriented personnel demand}

\section{1) Industry personnel demanding distribution}

According to National Industry Classification (GB/T 4754-2011) and the revised Three Industrial Classification Regulation (2012) ${ }^{[6]}$, with the object of previous college graduates, it is ape to investigate the industry distribution of personnel demanding. Take 2007-2012 sessions of accounting graduates of Hangzhou Dianzi University for example in the following contents.

\section{2) Judgment of industry hierarchical classification}

Based on industry personnel demand distribution and industry hierarchical classification standard, the level of industry personnel demand and the category of major setup can be determined. The top five personnel demanding industries ranking in this university are business service industry (L), manufacturing industry $(\mathrm{C})$, financial industry $(\mathrm{J})$, education $(\mathrm{P})$ and public administration $(\mathrm{S})$ respectively. Accordingly, their levels of personnel demand are $\mathrm{A}, \mathrm{E}, \mathrm{I}, \mathrm{I}$ and $\mathrm{O}$, and their categories of major setup are E, I, U, O and U, as shown in Table 3.

\section{3) Train-path oriented industry}

Based on the levels of industry demand and categories of major setup, it is necessary for major setup to provide major adjustment mechanism oriented by industry demand. The orientation of major setup should be matched with the distribution characteristics of industry personnel demand. Therefore, the industry-oriented personnel training paths are: implement in priority business service industry (L) personnel training outline (A); focus on the implement of manufacturing industry $(\mathrm{C})$ personnel training outline (E); accelerate the implement of financial industry $(\mathrm{J})$ personnel training outline (I); steadily implement education $(\mathrm{P})$ personnel training outline $(\mathrm{I})$; orderly implement the public administration(S) personnel training outline (I).

Table 3. Analysis of AEIOU on industry.

\begin{tabular}{lllll}
\hline Industry and Level Category & $\mathbf{2 0 0 7 - 2 0 1 2}$ & Index(\%) & Talent Demand & Major Setup \\
\hline Business Services (L) & 439 & 32.52 & $\mathrm{~A}$ & $\mathrm{E}$ \\
Manufacturing (C) & 328 & 24.30 & $\mathrm{E}$ & $\mathrm{I}$ \\
Financial Sector (J) & 258 & 19.11 & $\mathrm{I}$ & $\mathrm{U}$ \\
Education (P) & 191 & 14.15 & $\mathrm{I}$ & $\mathrm{O}$ \\
Public Administration (S) & 134 & 9.93 & $\mathrm{O}$ & $\mathrm{U}$ \\
\hline
\end{tabular}

\subsection{The training paths based on enterprise- directed personnel demand}

\section{1) Enterprise personnel demanding distribution}

According to recent statistics on university graduate employment, it is easy to look into the enterprise distribution of personnel demanding. Pan-China Certified Public Accountants, Hangzhou Dianzi University, SHU LUNPAN
Certified Public Accountants, Bank of China, Rural Commercial Bank, IMC accounting firm, Agricultural Bank of China, Construction Bank, Industrial and Commercial Bank of China and Zhonghui accounting firm are ranking the top ten demanding enterprises in the school of accounting.

\section{2) Judgment of enterprise hierarchical classification}


According to the enterprise personnel demanding distribution and enterprise hierarchical classification standard, the level of enterprise personnel demand and the category of major setup can be determined. The personnel demanding levels of Pan-China Certified Public Accountants, Hangzhou Dianzi University, SHU LUNPAN Certified Public Accountants, Bank of China and Rural Commercial Bank are A, I, I, O, and O respectively. Accordingly, their categories of major setup are $\mathrm{E}, \mathrm{O}, \mathrm{O}, \mathrm{U}$ and $\mathrm{U}$, as shown in Table 4.

\section{3)Train-path directed enterprise}

Based on the levels of enterprise demand and categories of major setup, it is necessary for major setup to provide major adjustment mechanism directed by enterprise demand. In major setup direction, it is necessary to match the distribution characteristics of enterprise personnel demand. Based on this, the enterprise-directed personnel training paths are: determine in priority Pan-China Certified Public Accountants and SHU LUNPAN Certified Public Accountants personnel training guide (A); focus on the implement of Hangzhou Dianzi University and University of Glasgow personnel training guide (E); accelerate to determine Bank of China and Rural Commercial Bank personnel training guide (I).

Table 4. Analysis of AEIOU on enterprise.

\begin{tabular}{lllll}
\hline Enterprise and Level Category & $\mathbf{2 0 0 7 - 2 0 1 2}$ & Analysis Index & Talent Demand & Major Setup \\
\hline Pan-China Certified Public Accountants & 135 & 22.5 & $\mathrm{~A}$ & $\mathrm{E}$ \\
Hangzhou Dianzi University & 75 & 12.5 & $\mathrm{I}$ & $\mathrm{O}$ \\
SHU LUNPAN Certified Public Accountants & 64 & 10.7 & $\mathrm{I}$ & $\mathrm{O}$ \\
Bank of China & 30 & 5 & $\mathrm{O}$ & $\mathrm{U}$ \\
Rural cooperative banks & 30 & 5 & $\mathrm{O}$ & $\mathrm{U}$ \\
\hline
\end{tabular}

\subsection{The training paths based on occupation- guided personnel demand}

\section{1) Occupation personnel demanding distribution}

According to university employment information and occupation demanding position, it is prone to be statistic of the occupation distribution of personnel demanding. The occupation positions for accounting graduates include accounting, auditing, financial, recruitment and other positions. In addition, recruitment positions include finance and bank, postgraduate, study abroad, government institutions and other positions.

\section{2) Judgment of occupation hierarchical classification} According to the occupation personnel demanding distribution and occupation hierarchical classification standard, the level of occupation personnel demand and the category of major setup can be determined by AEIOU method. The demanding levels of accounting positions and recruitment positions are A, the demanding levels of audit- ing positions and finance positions are E and I, while other positions are U. The existing major setup categories are judged as A, U, I, I, and U, as shown in Table 5.

\section{3) Train-path guided occupation}

Compared the levels of occupation demand with the categories of major setup, it is necessary for major setup to provide major level, scale and structure adjustment mechanism guided by occupation demand. In guidance of major setup, major level, scale and structure are consistent with the characteristics of occupation personnel demanding. Therefore, the occupation-guided personnel training paths are: optimize and implement personnel training plans of accounting positions (A); promote and implement personnel training plans of recruitment positions (A); expand and implement personnel training plans of auditing positions(E); adjust and implement personnel training plans of financial positions (I).

Table 5. Analysis of AEIOU on Occupation.

\begin{tabular}{|l|c|c|c|c|}
\hline Occupation and Level Category & $\mathbf{2 0 0 7 - 2 0 1 2}$ & Index (\%) & Talent Demand & Major Setup \\
\hline Accounting Position & 615 & 35.04 & $\mathrm{~A}$ & $\mathrm{~A}$ \\
\hline Recruitment Position & 549 & 31.28 & $\mathrm{~A}$ & $\mathrm{U}$ \\
\hline Audit Position & 352 & 20.06 & $\mathrm{E}$ & $\mathrm{I}$ \\
\hline Finance Position & 206 & 11.74 & $\mathrm{I}$ & $\mathrm{I}$ \\
\hline Other Position & 33 & 1.88 & $\mathrm{U}$ & $\mathrm{U}$ \\
\hline
\end{tabular}

\section{Acknowledgment}

This preliminary work is mainly supported by SCG257 to Zhenyun Zhou through Education Scientific Planning Research Subject of Zhejiang Research Institute of Education Science in 2012, and partially supported by XGZD01 to Zhenyun Zhou through Higher Education Research Subject of Hangzhou Dianzi University in 2011. This later work is not only sponsored by KYF145613006 to Zhenyun Zhou through humanities and social science research funded project of Hangzhou Dianzi University during the period of January 2013 to December 2014, but also supported by YB1428 to Yiqi Mao through Higher Education Research Subject of Hangzhou Dianzi University during the period of June 2014 to June 2015.

\section{References}

1. Kai Yu, Chengwen Hong, Bangping Ding, Xiaoguang Shi. Foreign higher education teaching content and course system reform trend [J]. China University Teaching, 1998, (1):44-47. 
2. Zhou Zhenyun, Jingjing Wang, Weiwei Zheng. Analysis and strategies on the model of students difficulties in their job-hunting [J]. Journal of Hang Zhou Dianzi University (Social Sciences), 2011, 7(3): 75-78.

3. Rongwei Yang. Research in the Establishment and Adjustment of Specialized Subjects in Higher Education Institutions [D]. Shanghai: Graduate School of East China Normal University, 2006:2-8.

4. Zhenyun Zhou, Yongbo Liu, Daoming Wang and Danqin Ye. Adjustment Mechanism of Major Setup Based on Employment-oriented AEIOU Method [C]. 2013 International Conference on Applied Social
Science Research (ICASSR 2013). Proceedings of 2013 International Conference on Applied Social Science Research, France: Atlantis Press, 2013:56-59.

5. Zhenyun Zhou, Daoming Wang, Jingyi Xing. Study on Employment-Oriented AEIOU Method and Hierarchical Classification Training Mode[C], The 3rd Conference on Creative Education (CCE 2013). Proceedings of Conference on Creative Education, USA: Scientific Research Publishing,2013:250-254.

6. National Bureau of Statistics. The three industrial classification regulations [EB/OL]. http://www.stats. gov.cn/tjbz/t20130114_402865889.htm, 2013-01-14. 